\title{
Decreased Physical Activity
}

National Cancer Institute

\section{Source}

National Cancer Institute. Decreased Physical Activity. NCI Thesaurus. Code C122444.

A reduction in the normal physical activity for an individual. 